\title{
A INSERÇÃO INTERNACIONAL DA SOCIEDADE BRASILEIRA DE QUÍMICA
}

\author{
Antonio S. Mangrich* \\ Departamento de Química, Universidade Federal do Paraná, CP 19081, 81531-970 Curitiba - PR, Brasil \\ Hans Viertler \\ Instituto de Química, Universidade de São Paulo, CP 26077, 05513-970 São Paulo - SP, Brasil \\ Paulo C. Vieira \\ Departamento de Química, Universidade Federal de São Carlos, CP 676, 13560-970 São Carlos - SP, Brasil
}

THE INTERNATIONAL INSERTION OF THE SOCIEDADE BRASILEIRA DE QUÍMICA. This paper presents some aspects involved in the internationalization of SBQ. The importance of journals, meetings and agreements in this process is discussed.

Keywords: Sociedade Brasileira de Química; internationalization.

\section{INTRODUÇÃO}

Desde a sua criação, em oito de julho de 1977, a Sociedade Brasileira de Química tem promovido a organização e o desenvolvimento da Química Brasileira, dentro e fora do País ${ }^{1}$. Em 1977, os químicos apresentavam seus trabalhos durante as Reuniões Anuais da SBPC (Sociedade Brasileira para o Progresso da Ciência). A Associação Brasileira de Química (ABQ) não contava mais com os bioquímicos, que fundaram a SBBq, em 1965. Perdeu ainda os engenheiros químicos para a nova ABEQ (Associação Brasileira de Engenharia Química), em 1975. O Brasil necessitava de uma nova entidade química organizada e atenta às necessidades dos profissionais da área².

Já no início houve intenção de promover a inserção internacional da SBQ através da aproximação com outras sociedades congêneres. $\mathrm{O}$ primeiro contato que se tem notícia foi o da visita do primeiro secretário geral da SBQ, Prof. Eduardo Peixoto, à The Royal Society of Chemistry.

A internacionalização da SBQ é marcada por várias formas de atuação, como a criação de revistas de circulação internacional, as Reuniões Anuais e reuniões específicas de suas divisões científicas, os protocolos de intenções com sociedades científicas de outros países etc.

\section{AS REVISTAS}

A revista Química Nova (QN) foi criada juntamente com a SBQ para ser o seu órgão de divulgação ${ }^{1}$. Segundo o primeiro editorial publicado “(...) a SBQ lança QUÍMICA NOVA numa tentativa de tornar a Química útil àqueles que leiam português e, o que é mais importante, dar aos que desejam, uma oportunidade de colaborar e ser um pouco mais útil para a sociedade em que vivem como quími-

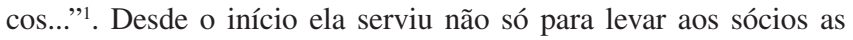
informações referentes à Sociedade, mas também para divulgar artigos científicos. Mesmo sendo uma revista que publica majoritariamente trabalhos em português, a $\mathrm{QN}$, depois da sua indexação em bases de dados internacionais, como Chemical Abstracts em 1980 e Web of Science, em 1995, é sem dúvida um componente importante para a inserção internacional da SBQ. Com seu Fator de Impacto acima de 0,6 nos últimos anos, insere-se entre as maiores revistas de Química do Hemisfério Sul. É interessante lembrar que no primeiro

*e-mail: mangrich@quimica.ufpr.br editorial de QN, seu editor, Prof. Peixoto, ressaltava a importância da SBQ ter uma revista que publicasse artigos científicos em português ${ }^{1 .} \mathrm{O}$ que talvez ele não imaginasse naquele tempo é que a $\mathrm{QN}$, mesmo publicando basicamente em português, seria lida em todo o mundo através da rede mundial de computadores.

Hoje, certamente a maior internacionalização da SBQ está representada pelo Journal of the Brazilian Chemical Society (JBCS), que teve seu primeiro número publicado no início de 1990 (Jan/ Abr). Desde sua criação, tem como filosofia a proposta de divulgar trabalhos científicos originais na área de Química, nos moldes internacionais, aberta a todo e qualquer autor brasileiro ou estrangeiro, que viesse a submeter artigos e notas de comunicações, originais e inéditas, ao corpo editorial da revista. Publicando em língua inglesa o JBCS tem uma grande visibilidade internacional com Fator de Impacto acima de um, o que o torna uma das revistas mais citadas da América Latina, entre todas as áreas. A sua excepcional aceitação pela comunidade internacional reflete-se também no grande número de autores estrangeiros que submetem e publicam seus artigos nesta revista. Tanto o JBCS como a $Q N$ estão disponíveis nas formas impressas e eletrônicas, com acesso livre através da Web, sendo esta, também, uma forma da SBQ ganhar visibilidade e inserção internacional ${ }^{3}$.

O JBCS tem servido constantemente de meio de interação com as Sociedades de Química de outros países. As divisões científicas da SBQ têm utilizado números especiais do JBCS para publicar trabalhos de suas reuniões, muitas delas em conjunto ("joint") com divisões congêneres pertencentes a Sociedades de Química estrangeiras. O número de Mar/Abr de 1997 foi um "Special Issue on Eletrochemistry" do qual constavam trabalhos apresentados durante o XII CIBAE. Em Nov/Dez de 2003 publicou-se o número referente ao "XI Brazilian Meeting on Inorganic Chemistry" que, na realidade, foi o "Joint Brazilian/Italian Inorganic Chemistry Meeting". Em 2004, o JBCS tornou-se a primeira revista científica editada na América Latina com fator de impacto ISI superior a um. O JBCS volume 16, número 3 (Mai/Jun) 2005 foi conjunto com a Sociedad Química de México. No editorial deste número Guillermo Delgado (UNAM-México) e Roberto M. Torresi (USP-Brasil) afirmaram que "as Sociedades Químicas de diversos países têm empregado esforços, agregando os profissionais de pesquisa, educação, desenvolvimento tecnológico e industrial. As Sociedades Químicas do México e do Brasil não têm sido exceção; têm organizado, com o decorrer dos anos, reuniões científicas e de educação em Química e publicado edições pertinentes, entre outras atividades. As reuni- 
ões profissionais, os Congressos Nacionais, assim como os Congressos Latino-Americanos de Química, têm desempenhado papel de destaque no âmbito desta ciência em nossos países".

\section{AS REUNIÕES ANUAIS}

A SBQ sempre teve um extremo cuidado na organização de suas Reuniões Anuais (RASBQ). Com uma característica científica forte, as suas programações científicas continuamente contemplaram a participação de convidados estrangeiros, que muito contribuíram para dar maior credibilidade e visibilidade à nossa Sociedade no exterior. Em várias ocasiões tivemos reuniões específicas onde a inserção internacional da SBQ era clara. No ano de 2000, na $23^{\mathrm{a}}$ RASBQ, a iniciativa de internacionalização culminou com uma reunião conjunta com Portugal e várias atividades foram desenvolvidas e, como conseqüência, tivemos naquele ano uma participação bastante representativa de pesquisadores portugueses. Essa Reunião Anual teve como tema "Brasil 500 - A Ligação Química Brasil-Portugal".

No ano 2001, a 24 a RASBQ, com o tema "A Química na América Latina - Integração e Desenvolvimento Sustentável”, registrou a presença de um grande número de Presidentes e representantes de várias Sociedades de Química de outros países, permitindo com a discussão desse assunto colocar a SBQ no centro de uma temática da maior relevância para a região, o papel da Química no desenvolvimento sustentável.

A inserção internacional, em termos de RAs, teve grande destaque com a organização nos dias 30/05 a 02/06 de 2004, na cidade de Salvador - BA, do congresso da Federación Latinoamericana de Asociaciones Químicas; o XXVI Congreso Latinoamericano de Química (CLAQ), durante a 27 ${ }^{\mathrm{a}} \mathrm{RASBQ}$. O evento contou com delegações de diversos países latino-americanos, além de um número significativo de pesquisadores dos EUA. Inúmeras atividades marcaram um excelente congresso e, entre elas poderíamos destacar os workshops, organizados em colaboração com a American Chemical Society (ACS), "Environmental Chemistry" e "Modern Science and its Potential for Biotechnology in Latin America".

Como consequiência da organização do XXVI CLAQ o presidente da SBQ na ocasião, Prof. Paulo C. Vieira, foi eleito pela assembléia da FLAQ como Diretor Presidente da Federação pelo período de 2 anos, a partir do final de maio de 2004, e o Prof. Jailson B. de Andrade, do Conselho Consultivo da SBQ, para Secretário Geral da entidade.

Deve-se lembrar, todavia, que a organização do XXVI CLAQ teve que ser trabalhada por longos anos e envolveu o envio de delegações da SBQ a vários congressos, desde 1996 no Chile, 1998 em Porto Rico, 2000 no Peru e, finalmente, em 2002, no México, quando o Brasil foi escolhido para sediar o congresso em 2004, sendo a SBQ a entidade organizadora.

No ano de 2007 tivemos a $30^{\text {a }}$ RASBQ, durante a qual se comemoraram os 30 anos de existência da SBQ.

À cerimônia de abertura da 30a RASBQ compareceu o Cônsul Geral do Reino Unido, em São Paulo, Dr. Martin Raven, acompanhado de outros membros da representação diplomática. Em termos de inserção internacional tivemos dois simpósios conjuntos com sociedades de química de outros países. Um deles foi o:
"Workshop on US/Brazil Research Collaboration: Biomass Conversion to Biofuels, Biomaterials, and Chemicals" nos dias 3031 de maio de 2007. O outro foi organizado com a RSC "Chemistry and innovation - from spin-out to market". A imprensa especializada deu ampla divulgação às atividades realizadas ${ }^{4-9}$.

\section{PROTOCOLOS DE INTENÇÕES COM SOCIEDADES CIENTÍFICAS}

A SBQ mantém protocolos de intenções de colaborações com várias sociedades científicas de química, entre elas: The Royal Society of Chemistry; Gesellschaft Deutscher Chemiker (Sociedade de Química da Alemanha); Sociedad Química Del Peru; American Chemical Society; Sociedad Química de México; Asociación Química Argentina; Sociedad Venezolana de Química, Sociedad Chilena de Química; Société Française de Chimie e Sociedade Portuguesa de Química. Em razão destes protocolos têm sido implementados vários contatos e colaborações entre pesquisadores brasileiros e daqueles países.

Para a Reunião comemorativa de 30 anos, a SBQ convidou Presidentes de várias Sociedades de Química para estarem presentes em Águas de Lindóia.

\section{CONCLUSÃO}

Todo empreendimento bem pensado e executado cumpre suas finalidades de forma adequada. Os colegas que em 1977 criaram a SBQ o fizeram de modo bem planejado. Ao verificarmos a história econômica e do desenvolvimento geral do Brasil nos últimos 30 anos observamos que a SBQ tem cumprido o seu papel de organizar, divulgar e promover o desenvolvimento da Química brasileira. A inserção internacional da SBQ foi objetivo procurado desde sua criação. Manter a Química brasileira em constante contato e colaboração com nossos vizinhos latino-americanos, e com outros países, foi atitude inteligente e de boa administração de nossos dirigentes. A permanente preocupação com a presença de pesquisadores de outros países nas nossas reuniões científicas, a elaboração de protocolos de intenções com as sociedades congêneres estrangeiras e a criação e manutenção de nossas revistas científicas, em muito bom nível, foram atitudes acertadas e fundamentais para chegarmos aos 30 anos da SBQ de maneira a provocar orgulho em todos os seus associados.

\section{REFERÊNCIAS}

1. Peixoto, E. M. A.; Quim. Nova 1978, 1, 26.

2. Bechara, E.; Viertler, H.; Quim. Nova 1997, 20 (Especial), 63.

3. www.sbq.org.br

4. Começa a Reunião Anual da SBQ; http://www.agencia.fapesp.br/ boletim_dentro.php?id=7238, acessada em Agosto 2007.

5. Zucco, C.; Formação básica, http://www.agencia.fapesp.br/boletim_ dentro.php?id=7242, acessada em Agosto 2007.

6. Barreiro, E.; Construção da Inovação; http://www.agencia.fapesp.br/ boletim_dentro.php?id=7249, acessada em Agosto 2007.

7. Mangrich, A. S.; Mercado em expansão, http://www.agencia.fapesp.br/ boletim_dentro.php?id=7251, acessada em Agosto 2007.

8. Ritter, S.; Chem. Eng. News 2007, 85 (23), 9.

9. Ritter, S. K.; Chem. Eng. News 2007, 85 (26), 15. 